\title{
A model for multi-directional cyclic shear-induced pore water pressure and settlement on clays
}

\author{
Tran Thanh Nhan $^{1,2}$ (D) Hiroshi Matsuda ${ }^{1} \cdot$ Hidemasa Sato $^{1,3}$
}

Received: 3 June 2016/ Accepted: 7 January 2017/Published online: 21 January 2017

(C) The Author(s) 2017. This article is published with open access at Springerlink.com

\begin{abstract}
An estimation method for earthquake-induced pore water pressure and the postearthquake settlement of soft clay was developed by focusing on its Atterberg's limits and the direction of cyclic shearing. To clarify the fundamental characteristics of clays with different Atterberg's limits under multi-directional cyclic shear, normally consolidated specimens of Kaolinite clay, Tokyo bay clay and Kitakyushu clay were subjected to cyclic simple shear under the undrained condition with various cyclic shear directions and shear strain amplitudes, followed by the dissipation of cyclic shear-induced pore water pressure. The effects of undrained cyclic shear on the pore water pressure accumulation and postcyclic settlement were observed, and relationships with Atterberg's limits were then investigated. In conclusion, the pore water pressure accumulation and post-cyclic settlement induced by multi-directional cyclic shear increase considerably to a higher level compared with those generated by the uni-directional one and such a tendency is evident for clays with a wide range of Atterberg's limits. Comparisons of the results indicate that the soil with higher plasticity index shows the lower pore water pressure accumulation and post-cyclic settlement, irrespective of number of strain cycles and shear strain amplitude. Based on these results, a model for earthquake-induced pore water pressure and postearthquake settlement was developed by incorporating the Atterberg's limits as a function of experimental constants and the practical applicability was confirmed.
\end{abstract}

Keywords Clay · Plasticity index · Pore water pressure $\cdot$ Settlement $\cdot$ Undrained cyclic shear

Tran Thanh Nhan

nhan@yamaguchi-u.ac.jp; nhan.hueuni@gmail.com

Yamaguchi University, 2-16-1 Tokiwadai, Ube, Yamaguchi 755-8611, Japan

2 Hue University of Sciences - Hue University, 77 Nguyen Hue, Hue City, Vietnam

3 Fukken Co. Ltd., 2-10-11 Hikarimachi, Higashi-ku, Hiroshima, Japan 


\begin{tabular}{|c|c|}
\hline \multicolumn{2}{|c|}{ Abbreviations } \\
\hline$A$ & Experimental constant \\
\hline$\alpha$ & Experimental parameter \\
\hline$B$ & Experimental constant \\
\hline$B$-value & Pore pressure coefficient induced by undrained static loading \\
\hline$\beta$ & Experimental parameter \\
\hline$C$ & Experimental constant \\
\hline$C_{c}$ & Virgin compression index \\
\hline$C_{d y n}$ & Cyclic recompression index \\
\hline$C_{d y n U}$ & Cyclic recompression index induced by uni-directional cyclic shear \\
\hline$C_{d y n M}$ & Cyclic recompression index induced by multi-directional cyclic shear \\
\hline$D \varepsilon$ & $\begin{array}{l}\text { Normalized post-cyclic settlement in strain between multi-directional and } \\
\text { uni-directional cyclic shears }\end{array}$ \\
\hline$D \varepsilon_{\max }$ & $\begin{array}{l}\text { Maximum normalized post-cyclic settlement in strain between multi- } \\
\text { directional and uni-directional cyclic shears }\end{array}$ \\
\hline$D U$ & $\begin{array}{l}\text { Normalized pore water pressure ratio between multi-directional and uni- } \\
\text { directional cyclic shears }\end{array}$ \\
\hline$D U_{\max }$ & $\begin{array}{l}\text { Maximum normalized pore water pressure ratio between multi-directional } \\
\text { and uni-directional cyclic shears }\end{array}$ \\
\hline$f$ & Frequency of cyclic shear strain \\
\hline$F$ & Experimental parameter \\
\hline$\delta$ & Maximum horizontal displacement of specimen \\
\hline$\Delta e$ & Change of the void ratio \\
\hline$\Delta h$ & Settlement of specimen \\
\hline$\Delta \varepsilon$ & $\begin{array}{l}\text { Difference of post-cyclic settlement in strain between multi-directional and } \\
\text { uni-directional cyclic shears }\end{array}$ \\
\hline$\Delta \varepsilon_{\max }$ & $\begin{array}{l}\text { Maximum difference of post-cyclic settlement in strain between multi- } \\
\text { directional and uni-directional cyclic shears }\end{array}$ \\
\hline$\Delta U$ & $\begin{array}{l}\text { Difference of pore water pressure ratio between multi-directional and uni- } \\
\text { directional cyclic shears }\end{array}$ \\
\hline$\Delta U_{\max }$ & $\begin{array}{l}\text { Maximum difference of pore water pressure ratio between multi-directional } \\
\text { and uni-directional cyclic shears }\end{array}$ \\
\hline$e_{0}$ & Initial void ratio \\
\hline$\varepsilon_{M}$ & Post-cyclic settlement in strain induced by multi-directional cyclic shear \\
\hline$\varepsilon_{U}$ & Post-cyclic settlement in strain induced by uni-directional cyclic shear \\
\hline$\varepsilon_{V}$ & Post-cyclic settlement in strain \\
\hline$G$ & Experimental parameter \\
\hline$G L$ & Ground level \\
\hline$G_{s}$ & Specific gravity \\
\hline$\gamma$ & Shear strain amplitude \\
\hline$\gamma_{D \varepsilon \max }$ & Shear strain amplitude at which $D \varepsilon$ reaches $D \varepsilon_{\max }$ \\
\hline$\gamma_{\triangle \varepsilon m a x}$ & Shear strain amplitude at which $\Delta \varepsilon$ reaches $\Delta \varepsilon_{\max }$ \\
\hline$\gamma_{D U \max }$ & Shear strain amplitude at which $D U$ reaches $D U_{\max }$ \\
\hline$\gamma_{\Delta U \max }$ & Shear strain amplitude at which $\Delta U$ reaches $\Delta U_{\max }$ \\
\hline$\gamma_{d y n}$ & Equivalent uniform shear strain amplitude \\
\hline$\gamma_{\max }$ & Maximum shear strain amplitude of irregular strain time histories \\
\hline$\gamma_{\operatorname{maxNS}}$ & $\begin{array}{l}\text { Maximum shear strain amplitude in } N S \text { direction of irregular strain time } \\
\text { histories }\end{array}$ \\
\hline
\end{tabular}




$\begin{array}{ll}\gamma_{\text {max } E W} & \text { Maximum shear strain amplitude in } E W \text { direction of irregular strain time } \\ \gamma_{x} & \text { histories } \\ \gamma_{y} & \text { Shear strain amplitude in } X \text { direction } \\ h_{0} & \text { Shear strain amplitude in } Y \text { direction } \\ I_{p} & \text { Initial height of specimen } \\ m & \text { Plasticity index } \\ n & \text { Experimental constant } \\ N_{c y} & \text { Number of cycles } \\ \theta & \text { Equivalent effective number of cycles } \\ \sigma_{v 0} & \text { Phase difference } \\ \sigma_{v 0}^{\prime} & \text { Initial vertical stress } \\ S R R & \text { Initial vertical effective stress } \\ T & \text { Stress reduction ratio } \\ U_{d y n} & \text { Period of cyclic shear strain } \\ U_{d y n} / \sigma_{v 0}^{\prime} & \text { Pore water pressure induced by undrained cyclic shear } \\ \left(U_{d y n} / \sigma_{v 0}^{\prime}\right)_{M} & \text { Pore water pressure ratio induced by undrained cyclic shear } \\ & \text { Pore water pressure ratio induced by undrained multi-directional cyclic } \\ \left(U_{d y n} / \sigma_{v 0}^{\prime}\right)_{U} & \text { shear } \\ w_{L} & \text { Pore water pressure ratio induced by undrained uni-directional cyclic shear } \\ w_{p} & \text { Liquid limit }\end{array}$

\section{Introduction}

When a clay layer is subjected to cyclic shear under the undrained conditions, because of the short-term cyclic loading of earthquakes and also the low permeability of clayey layers, the pore water pressure is produced which is commonly called as cyclic shear-induced pore water pressure, and such a pore water pressure increase leads to the decrease in the effective stress. Since the cyclic shear-induced pore water pressure itself relates to the cyclic degradation of the soil and significantly affects its cyclic shear resistance, the accumulation of pore water pressure is therefore considered as an important parameter when studying and simulating the cyclic behavior of soil deposits under the undrained cyclic shear. In addition, the dissipation of the pore water pressure after undrained cyclic loading results in the instantaneous and long-term settlements which have been observed as a post-earthquake settlement after major earthquakes, e.g. Hyogo-ken Nanbu earthquake in 1995 (Matsuda 1997) or the Tohoku Earthquake in 2011 (Konagai et al. 2013).

During earthquakes, soil layers are subjected to multi-directional cyclic shear with different shear strain amplitudes and frequencies (Ansal et al. 2001; Matsuda et al. 2004). Figure 1 shows the orbit of acceleration and shear strain at GL-16 m depth in Port Island (Kobe, Japan) during Hyogo-ken Nanbu earthquake 1995 (Matsuda et al. 2004). It is seen in Fig. 1 that the soil layer is subjected to the multi-directional cyclic shear strain during earthquakes. For saturated sands, the problems regarding the cyclic shear-induced pore water pressure and settlement, and the effect of cyclic shear direction on their dynamic properties have been extensively studied by a number of researches (Pyke et al. 1975; Ishihara and Yamazaki 1980; Tokimatsu and Yoshimi 1982; Ishihara and Yoshimine 1992; Talaganov 1996; Matsuda et al. 2004, 2011) and taken into account for a long time (Japan 
(a)

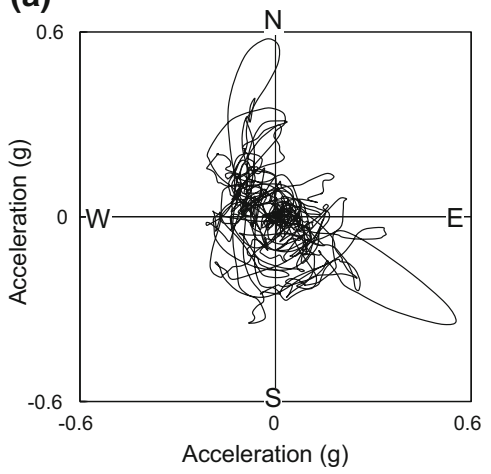

(b)

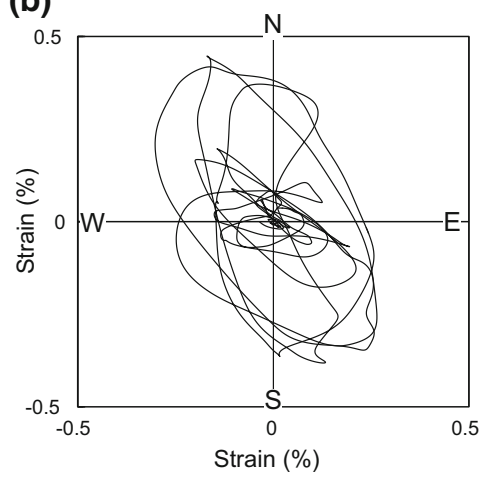

Fig. 1 Orbit of a acceleration and b shear strain at Hyogo-ken Nanbu earthquake 1995 (Matsuda et al. 2004)

Road Association 2002). When comparing the earthquake resistance of saturated clay with sand, soft cohesive soils are believed to be relatively stable because no liquefaction takes place even under strong motion by earthquakes (Hyodo et al. 1994, 1999; Yasuhara et al. 1992, 2001) and consequently, studies on the earthquake-induced pore water pressure and post-earthquake settlement of clay and sand are in different situations (Matasovic and Vucetic 1992; Yildirim and Ersan 2007), due to which the influence of the cyclic shear direction on the dynamic properties of clays has just been firstly mentioned by DeGroot et al. (1996) and observed for Kaolinite clay by Matsuda et al. (2013a, b). In addition, since the effects of relative movements of soil particle on the complex pore water pressure response are still insufficiently clarified, the so-called curve-fitting method is an appropriate approach for effective modelling of the pore water pressure accumulation and several models have been proposed for the case of strain-controlled cyclic shear e.g. Ohara et al. (1984), Ohara and Matsuda (1988), Matasovic and Vucetic (1992, 1995).

In this study, normally consolidated specimens of Kaolinite clay, Tokyo bay clay and Kitakyushu clay were adopted in several test series where the multi-directional cyclic simple shear tests were carried out under the undrained conditions with various cyclic shear directions and shear strain amplitudes and the effects of such as cyclic shear conditions and the Atterberg's limits of soil on the pore water pressure accumulation and on the recompression after cyclic shear were observed. A model for cyclic shear-induced pore water pressure accumulation and settlement were newly developed and its applicability was then confirmed.

\section{Undrained uni-directional and multi-directional cyclic simple shear tests on clays with different Atterberg's limits}

\subsection{Test apparatus}

Figure 2a shows the outline of the multi-directional cyclic simple shear test apparatus. This apparatus can apply any types of cyclic displacement at the bottom of specimen from two orthogonal directions by the electro-hydraulic servo system and at the same time, a predetermined vertical stress is also applied to the specimen by the aero-servo system. Photos 

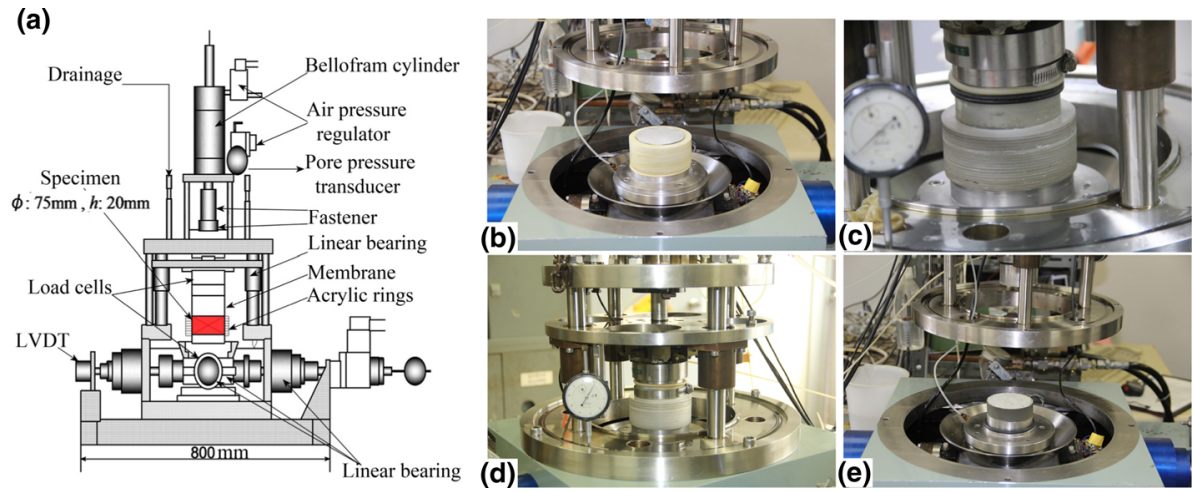

Fig. 2 a Outline of the multi-directional cyclic simple shear test apparatus, $\mathbf{b}$ slurry of sample after pouring into shear box, $\mathbf{c}$ soil specimen during pre-consolidation, $\mathbf{d}$ final setting before undrained cyclic shear and e soil specimen after recompression

of the apparatus and the specimen together with the shear box which is the Kjellman type are shown in Fig. 2b-e. The specimen is enclosed inside a rubber membrane and the outside of which is surrounded by a stack of acrylic rings. Each acrylic ring has $75.4 \mathrm{~mm}$ in inside diameter and $2 \mathrm{~mm}$ in thickness. In this condition, the specimen is prevented from the lateral deformation but permitted to the cyclic simple shear deformation.

\subsection{Samples and specimen}

The soils used in this study are Kaolinite clay, Tokyo bay clay and Kitakyushu clay. The grain size distribution curves and index properties of these soils are shown in Fig. 3 and Table 1, respectively.

In order to prepare the test specimen, samples were firstly mixed with de-aired water to form slurries having a water content of about $1.5 w_{L}$ and kept in big tanks under the constant water content. Secondly, each slurry was kept again in a smaller vessel for one day before de-airing in the vacuum cell. Thirdly, the slurry was poured into the shear box of the test apparatus (Fig. 2b) and pre-consolidated under the vertical stress $\sigma_{v 0}=49 \mathrm{kPa}$ until the pore water pressure at the bottom of the specimen is dissipated. After the preconsolidation, the dimension of specimen is $75 \mathrm{~mm}$ in diameter and about $20 \mathrm{~mm}$ in height and the initial void ratio is about $e_{0}=1.11-1.19,1.20-1.37$ and $1.61-1.81$ for Kaolin,

Fig. 3 Grain size distribution curves of soils

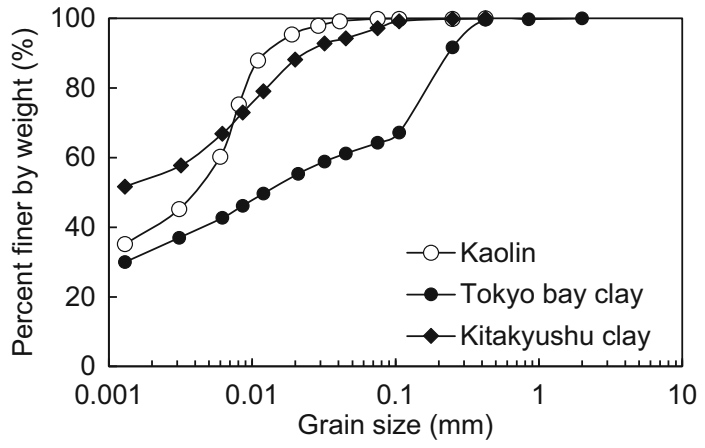


Table 1 Index properties of soils

\begin{tabular}{lccc}
\hline Property & Kaolin & Tokyo bay clay & Kitakyushu clay \\
\hline Specific gravity, $G_{s}$ & 2.71 & 2.77 & 2.63 \\
Liquid limit, $w_{L}(\%)$ & 47.8 & 66.6 & 98.0 \\
Plastic limit, $w_{P}(\%)$ & 22.3 & 25.0 & 34.2 \\
Plasticity index, $I_{p}$ & 25.5 & 41.6 & 63.8 \\
Compression index, $C_{c}$ & 0.31 & 0.46 & 0.60 \\
\hline
\end{tabular}

Tokyo bay clay and Kitakyushu clay, respectively. Then the coefficient of pore pressure of soil specimen was confirmed as $B$-value $>0.95$. This means that the required degree of saturation is satisfied.

\subsection{Test procedure and conditions}

After the pre-consolidation, the soil specimen was subjected to the strain-controlled cyclic simple shear under the undrained condition with the predetermined cyclic shear direction, shear strain amplitude $(\gamma)$ and number of cycles $(n)$. Following the undrained cyclic shear, drainage was allowed from the top surface of the specimen and the settlement was then measured with time.

Figure $4 a-d$ shows the deformation modes of specimen and the typical records of cyclic shear strains under the strain-controlled uni-directional and multi-directional cyclic shears.

(a)

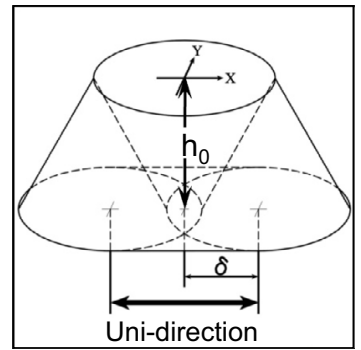

(c)

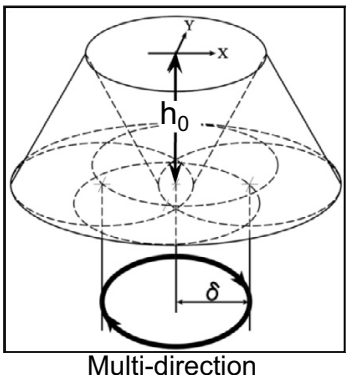

Multi-direction (b)

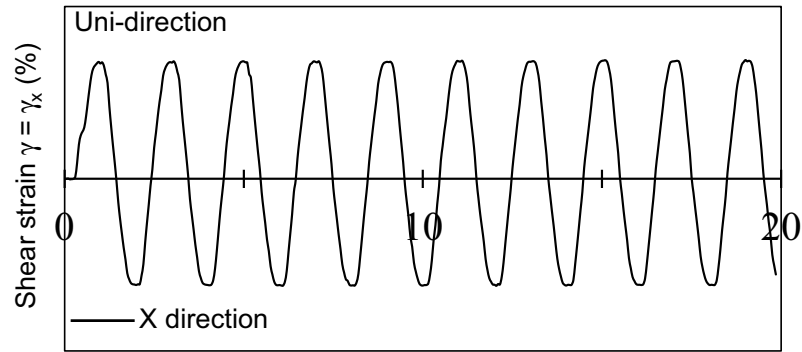

(d)

Time (s)

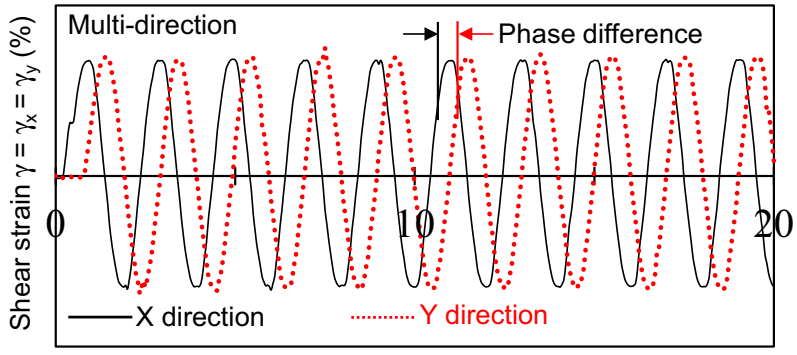

Time (s)

Fig. 4 Deformation modes of specimen and records of cyclic shear strains for $\mathbf{a}$, $\mathbf{b}$ uni-directional cyclic shear and c, d multi-directional cyclic shear 
The shear strain amplitude $\gamma$ is defined as a ratio of the maximum horizontal displacement $(\delta)$ to the initial height $\left(h_{0}\right)$ of specimen (Fig. $\left.4 \mathrm{a}, \mathrm{c}\right)$. In uni-directional test, the cyclic shear strain was applied to the specimen only in $X$ direction $\left(\gamma=\gamma_{x}\right)$ (Fig. 4a, b) and so the orbit of cyclic shear strain forms a linear line (Fig. 4a). In multi-directional test (Fig. 4c, d), the cyclic shear strain was simultaneously applied to the specimen in $X$ direction $\left(\gamma_{x}\right)$ and $Y$ direction $\left(\gamma_{y}\right)$ which are perpendicular to each other under the same shear strain amplitude $\left(\gamma=\gamma_{x}=\gamma_{y}\right)$ but with various phase differences $(\theta)$. Then the orbit shows an elliptical line for $0^{\circ}<\theta<90^{\circ}$ and a circle line for $\theta=90^{\circ}$ which is commonly known as a gyratory cyclic shear (Fig. 4c). A series of experiments were carried out as shown in Table 2. The wave form of the cyclic shear strain was sinusoidal (two way cyclic strain) with the period $T=2 \mathrm{~s}$ and the amplitude was changed in the range from $\gamma=0.05 \%$ to $\gamma=2.0 \%$. The number of cycles was fixed as $n=200$. For the multi-directional tests, the phase difference was changed as $\theta=20^{\circ}, 45^{\circ}, 70^{\circ}$ and $90^{\circ}$.

In order to meet the effect of cyclic loading frequency in nature, cyclic shear tests for investigating the dynamic behavior of soil deposits often apply the frequency $f \geq 0.1 \mathrm{~Hz}$ (Talesnick and Frydman 1992) and in the case of high frequency, potential effect of inertia force and inacurrate measurement of out-put data have been reported (Sangrey et al. 1969; Yong and Japp 1969). On the other hand, effects of loading frequency on the cyclic shearinduced pore water pressure and undrained cyclic shear strength have been confirmed to be negligible for clayey soils, at least in the range from $f=0.1 \mathrm{~Hz}$ to $f=3 \mathrm{~Hz}$ (Yasuhara et al. 1982, 1992; Hyde et al. 1993). In this study, the uni-directional and multi-directional cyclic shear tests were controlled as $f=0.5 \mathrm{~Hz}$ (i.e. $T=2 \mathrm{~s}$ ) and therefore the potential effects of testing frequency and/or inertia force can be ignored, and under such a loading frequency the accuracy of pore water pressure measurement has been confirmed (Ohara and Matsuda 1988; Matsuda and Ohara 1989; Matsuda and Nagira 2000; Matsui et al. 1992).

Table 2 Experimental conditions

\begin{tabular}{|c|c|c|c|c|}
\hline Period $T(\mathrm{~s})$ & Number of cycles $n$ & Soil & \multicolumn{2}{|c|}{ Shear strain amplitude $\gamma(\%)$} \\
\hline \multicolumn{5}{|c|}{ Uni-directional cyclic simple shear tests } \\
\hline \multirow[t]{3}{*}{2} & \multirow[t]{3}{*}{200} & Kaolin & \multicolumn{2}{|c|}{$0.1,0.2,0.3,0.4,0.5,0.6,0.8,1.0,1.2,2.0$} \\
\hline & & Tokyo bay clay & \multicolumn{2}{|c|}{$0.1,0.2,0.4,0.8,1.0,1.2,2.0$} \\
\hline & & Kitakyushu clay & \multicolumn{2}{|c|}{$0.1,0.2,0.4,0.8,1.0,1.2,2.0$} \\
\hline Period $T(\mathrm{~s})$ & Number of cycles $n$ & Soil & $\begin{array}{l}\text { Phase } \\
\text { difference } \theta\left(^{\circ}\right)\end{array}$ & $\begin{array}{l}\text { Shear strain } \\
\text { amplitude } \gamma(\%)\end{array}$ \\
\hline \multicolumn{5}{|c|}{ Multi-directional cyclic simple shear tests } \\
\hline \multirow[t]{3}{*}{2} & 200 & Kaolin & $20,45,70,90$ & $\begin{array}{l}0.1,0.2,0.3,0.4,0.5,0.6 \\
\quad 0.8,1.0,1.2,2.0\end{array}$ \\
\hline & & Tokyo bay clay & $20,45,70,90$ & $\begin{array}{l}0.05,0.1,0.2,0.4,0.8,1.0 \\
\quad 1.2,2.0\end{array}$ \\
\hline & & Kitakyushu clay & 45,90 & $\begin{array}{l}0.05,0.1,0.2,0.4,0.8,1.0 \\
\quad 1.2,2.0\end{array}$ \\
\hline
\end{tabular}




\section{Effects of cyclic shear direction and Atterberg's limits on the pore water pressure accumulation and settlement of clays subjected to undrained uni-directional and multi-directional cyclic shears}

\subsection{Pore water pressure accumulation and post-cyclic settlement of clays subjected to undrained uni-directional and multi-directional cyclic shears}

As a result of the undrained cyclic shear, pore water pressure increases with the number of cycles. In order to observe in detail the process of pore water pressure accumulation and the effect of cyclic shear direction on this process during the early stage of undrained cyclic shearing, the changes of pore water pressure ratio $\left(U_{d y n} / \sigma_{v 0}^{\prime}\right)$ on Kaolin, Tokyo bay clay and Kitakyushu clay are typically shown in Fig. 5 for uni-directional and multidirectional cyclic shears. Where the pore water pressure ratio is defined by the ratio of the cyclic shear-induced pore water pressure $\left(U_{d y n}\right)$ to the initial effective stress $\left(\sigma_{v 0}^{\prime}\right)$. In Fig. 5 including other figures, the experimental results for the uni-directional cyclic shear are denoted by "uni" while those for the multi-directional ones are notified by "multi" or symbolized by using the phase difference (e.g. " $\theta=90^{\circ}$ " in Fig. 5). It is seen in Fig. 5 that $U_{d y n} / \sigma_{v 0}^{\prime}$ increases with the number of cycles, regardless of the shear strain amplitude

(a)

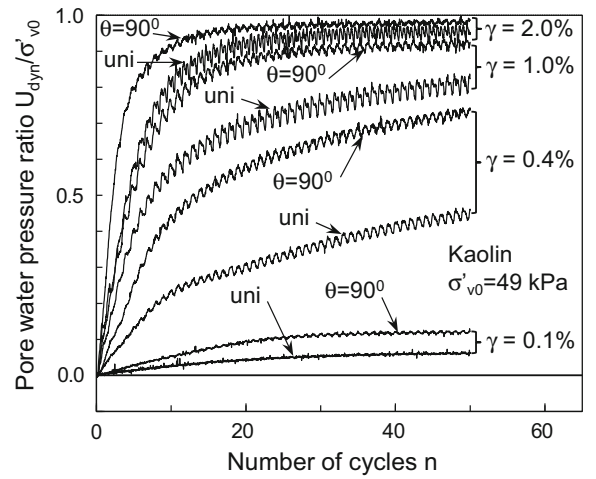

(b)

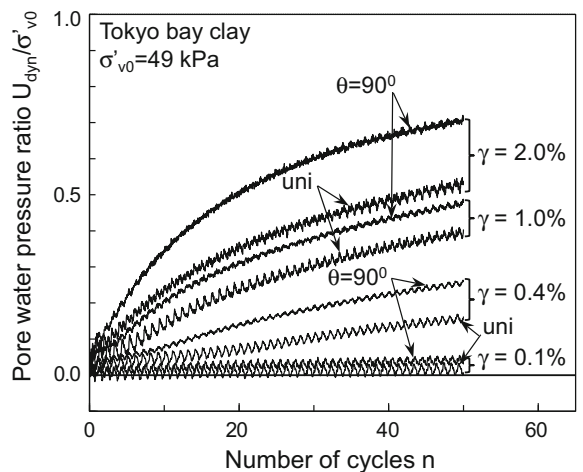

(c)

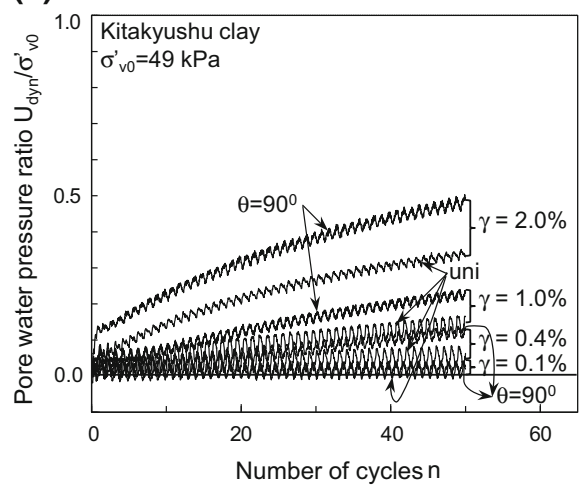

Fig. 5 Typical changes of $U_{d y n} / \sigma_{v 0}^{\prime}$ with $n$ for a Kaolin, b Tokyo bay clay and $\mathbf{c}$ Kitakyushu clay during undrained uni-directional and multi-directional cyclic shears $\left(\theta=90^{\circ}\right)$ 
(a)

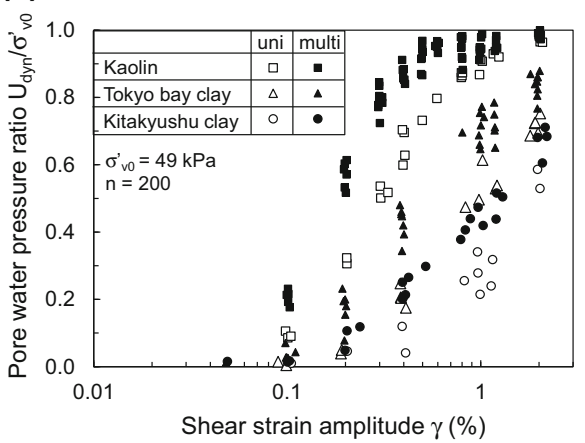

(b)

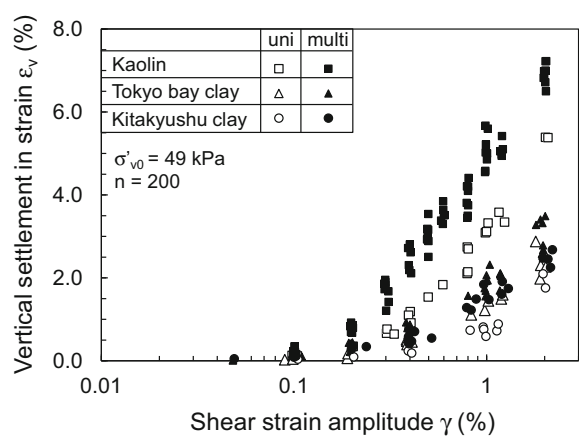

Fig. 6 Relations of $\mathbf{a} U_{d y n} / \sigma_{v 0}^{\prime}$ and $\mathbf{b} \varepsilon_{v}$ versus $\gamma$ for clays subjected to undrained uni-directional and multidirectional cyclic shears

and the Atterberg's limits of soil. At the same number of cycles, the larger the shear strain amplitude, the higher the ratio of pore water pressure. In addition, by using the typical data as shown in Fig. 5, the difference of $U_{d y n} / \sigma_{v 0}^{\prime}$ between multi-directional and uni-directional cyclic shears can be observed and therefore the effect of cyclic shear direction on the pore water pressure accumulation is confirmed for a wide range of shear strain amplitude and Atterberg's limits of clay. This behavior is different from those of saturated sands, in which the effect of cyclic shear direction on the reduction of effective stress becomes negligible when $\gamma \geq 0.3 \%$ (Matsuda et al. 2011, 2012). Therefore, since the cyclic stiffness and resistance of soil deposits are significantly affected by the pore water pressure accumulation and also relationships between the pore water pressure and the cyclic degradation of cohesive soil have been confirmed (Matasovic and Vucetic 1992, 1995), the higher pore water pressure accumulation suggests the significant disturbance and degradation of clays when subjected to the multi-directional cyclic shear.

Figure 5 indicates that the higher the Atterberg's limits of the soil, the slower the rate of pore water pressure accumulation leading to the lower $U_{d y n} / \sigma_{v 0}^{\prime}$ and post-cyclic settlement in strain $\left(\varepsilon_{v}, \%\right)$ on Kitakyushu clay and Tokyo bay clay compared with those on Kaolinite clay. In Fig. 6, the observed data of $U_{d y n} / \sigma_{v 0}^{\prime}$ and $\varepsilon_{v}$ are plotted against $\gamma$ for uni-directional and multi-directional tests with $n=200$. By using experimental results on normally and over-consolidated clays and sands, Vucetic and Dobry (1991) concluded that the plasticity index $\left(I_{p}\right)$ is one of the most important index properties when evaluating the dynamic behavior of fine-grained soil deposits, and that the soil with higher plasticity index shows more linear stress-strain response and less stiffness degradation at a given amplitude of cyclic shear strain. Therefore, in terms of the pore water pressure accumulation and the post-cyclic settlement which are focused in this study, significant effects of the cyclic shear direction and the Atterberg's limits on the cyclic response of clay are confirmed.

\subsection{Normalized pore water pressure ratio and post-cyclic settlement in relation to the plasticity index}

The above effects of cyclic shear direction on the cyclic shear-induced pore water pressure and settlement can be clarified more in detail for clays by considering the normalized values of $U_{d y n} / \sigma_{v 0}^{\prime}(D U)$ and $\varepsilon_{v}(D \varepsilon)$ in relation to the plasticity index of soil. $D U$ and $D \varepsilon$ are 
(a)

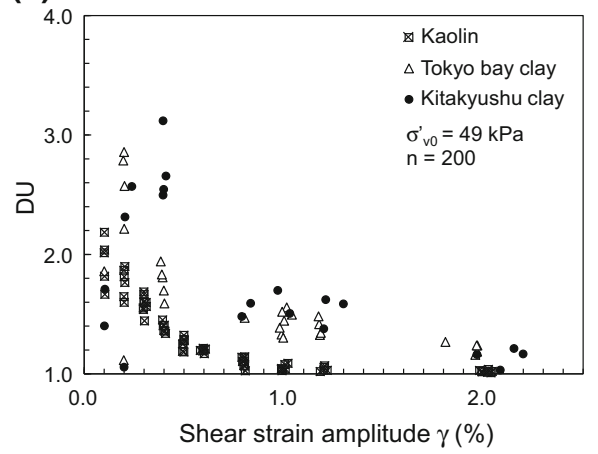

(b)

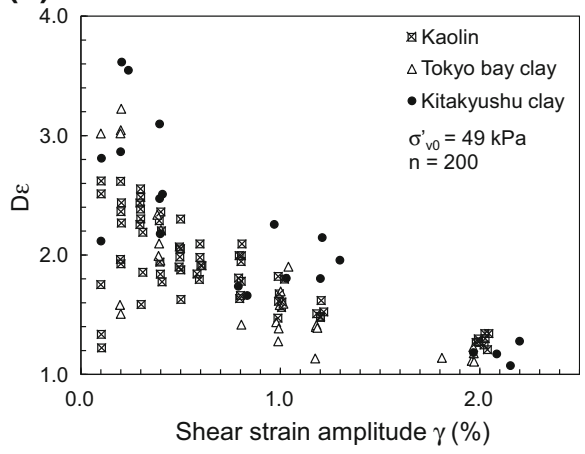

Fig. 7 Changes of $\mathbf{a} D U$ and $\mathbf{b} D \varepsilon$ with $\gamma$ for clays subjected to uni-directional and multi-directional cyclic shears

Fig. 8 Changes of $D U_{\max }$,

$D \varepsilon_{\max }, \gamma_{D U \max }$ and $\gamma_{\Delta D \varepsilon \max }$ with $I_{p}$

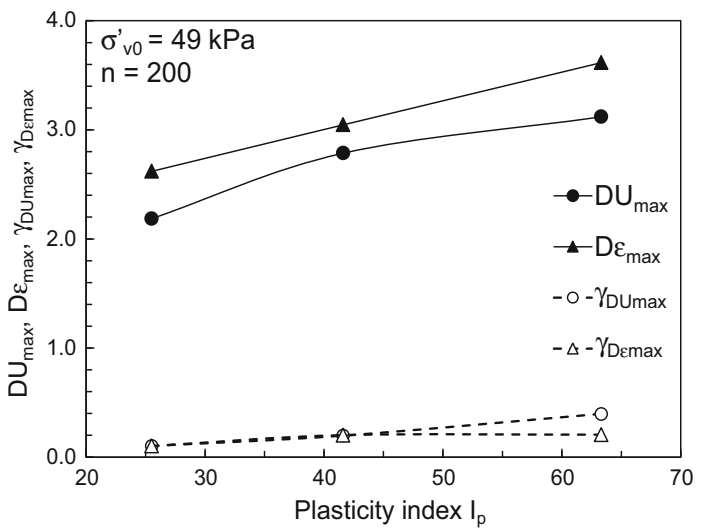

defined as the ratio of $U_{d y n} / \sigma_{v 0}^{\prime}$ and $\varepsilon_{v}$ induced by multi-directional cyclic shear $\left(\left(U_{d y n} /\right.\right.$ $\left.\sigma_{v 0}^{\prime}\right)_{M}$ and $\left.\varepsilon_{M}\right)$ to those induced by uni-directional one $\left(\left(U_{d y n} / \sigma_{v 0}^{\prime}\right)_{U}\right.$ and $\left.\varepsilon_{U}\right)$ and expressed by Eqs. (1) and (2) as follows:

$$
\begin{gathered}
D U=\left(U_{d y n} / \delta_{v 0}^{\prime}\right)_{M} /\left(U_{d y n} / \delta_{v 0}^{\prime}\right)_{U} \\
D \varepsilon=\varepsilon_{M} / \varepsilon_{U}
\end{gathered}
$$

The changes of $D U$ and $D \varepsilon$ with $\gamma$ are shown in Fig. 7 for Kaolin, Tokyo bay clay and Kitakyushu clay under the undrained cyclic shear with $n=200$. It is seen that $D U$ and $D \varepsilon$ are firstly at the highest values $\left(D U_{\max }\right.$ and $\left.D \varepsilon_{\max }\right)$ for relatively small shear strain amplitude of about $\gamma_{D U \max }=0.1-0.4 \%$ and $\gamma_{D \varepsilon \max }=0.1-0.2 \%$, then decreasing to smaller values (the shear strain amplitudes at which $D U$ and $D \varepsilon$ reach maximum as $D U_{\max }$ and $D \varepsilon_{\max }$, are denoted herein as $\gamma_{D U \max }$ and $\gamma_{D \varepsilon \max }$, respectively). The obtained values of $D U_{\max }, D \varepsilon_{\max }, \gamma_{D U \max }, \gamma_{D \varepsilon \max }$ are then plotted in Fig. 8 with $I_{p}$ to show their whole increasing tendencies. Meanwhile by using the similar calculation on a clay for a wide range of $n$ and $\gamma$, these parameters were confirmed to be unchanged with $n$, at least for the 
range of $n=10-200$ (Nhan et al. 2015). From Fig. 8, the relations as $\left(U_{d y n} / \sigma_{v 0}^{\prime}\right)_{M}=$ $2.2\left(U_{d y n} / \sigma_{v 0}^{\prime}\right)_{U}-3.1\left(U_{d y n} / \sigma_{v 0}^{\prime}\right)_{U}$ and $\varepsilon_{M}=2.6 \varepsilon_{U}-3.6 \varepsilon_{U}$ are obtained for the range of plasticity index from $I_{p}=25.5$ to 63.8 .

\subsection{Difference of pore water pressure ratio and post-cyclic settlement in relation to the plasticity index}

The effects of cyclic shear direction on the pore wate pressure accumulation and the postcyclic settlement can also be considered by using the difference of $U_{d y n} / \sigma_{v 0}^{\prime}(\Delta U)$ and $\varepsilon_{v}$ $(\Delta \varepsilon)$ between multi-directional cyclic shear and uni-directional one. These parameters are expressed by Eqs. (3) and (4) as follows:

$$
\begin{gathered}
\Delta U=\left(U_{d y n} / \sigma_{v 0}^{\prime}\right)_{M}-\left(\mathrm{U}_{\mathrm{dyn}} / \sigma_{\mathrm{v} 0}^{\prime}\right)_{\mathrm{U}} \\
\Delta \varepsilon=\varepsilon_{M}-\varepsilon_{\mathrm{U}}
\end{gathered}
$$

The changes of $\Delta U$ and $\Delta \varepsilon$ with $\gamma$ are shown in Fig. 9 for Kaolin, Tokyo bay clay and Kitakyushu clay. It is seen that $\Delta U$ and $\Delta \varepsilon$ firstly increase with $\gamma$ and reach their maximum $\left(\Delta U_{\max }\right.$ and $\left.\Delta \varepsilon_{\text {max }}\right)$ at a certain shear strain amplitude $\left(\gamma_{\Delta U \max }\right.$ and $\left.\gamma_{\Delta \varepsilon \max }\right)$ before decreasing (the shear strain amplitudes at which $\Delta U$ and $\Delta \varepsilon$ reach their maximum, $\Delta U_{\max }$ and $\Delta \varepsilon_{\text {max }}$, are denoted herein as $\gamma_{\Delta U \max }$ and $\gamma_{\Delta \varepsilon \max }$ ). When comparing the obtained results of $\Delta U_{\max }$ and $\Delta \varepsilon_{\max }$ as shown by plots in Fig. $10, \Delta U_{\max }$ decreases from 0.30 to 0.20 and $\Delta \varepsilon_{\max }$ falls from 2.6 to $1.0 \%$ when $I_{p}$ increases from 25.5 to 63.8 . Therefore, under the undrained cyclic shear with the same values of $n$ and $\gamma$, the pore water pressure in clayey layer increases by $20-30 \%$ when subjected to multi-directional cyclic shear leading to the higher settlement, by about $1.0-2.6 \%$ in strain, compared with those induced by the uni-directional one.

On the other hand, the results in Fig. 10 show the increasing tendencies of $\gamma_{\Delta U \max }$ and $\gamma_{\Delta \varepsilon \max }$ with $I_{p}$, from $\gamma_{\Delta U \max }=0.3$ to $1.2 \%$ and from $\gamma_{\Delta \varepsilon \max }=1.0$ to $1.2 \%$, respectively. Therefore, under the multi-directional cyclic shear with the same value of $n$, the shear strain amplitude required for $\Delta U_{\max }$ and $\Delta \varepsilon_{\max }$ becomes larger when the plasticity index of clay increasing. For Kaolinite clay with low plasticity, $\gamma_{\Delta \varepsilon \max }$ is considerably higher than

(a)

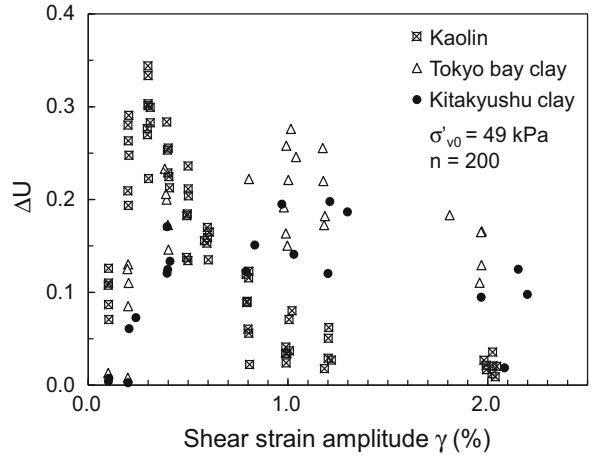

(b)

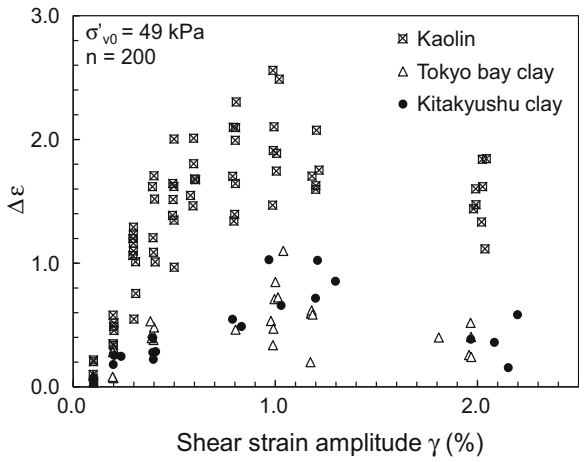

Fig. 9 Changes of $\mathbf{a} \Delta U$ and $\mathbf{b} \Delta \varepsilon$ with $\gamma$ for clays subjected to uni-directional and multi-directional cyclic shears 
Fig. 10 Tendencies of $\Delta U_{\max }$, $\Delta \varepsilon_{\max }, \gamma_{\Delta U \max }$ and $\gamma_{\Delta \varepsilon \max }$ with $I_{p}$

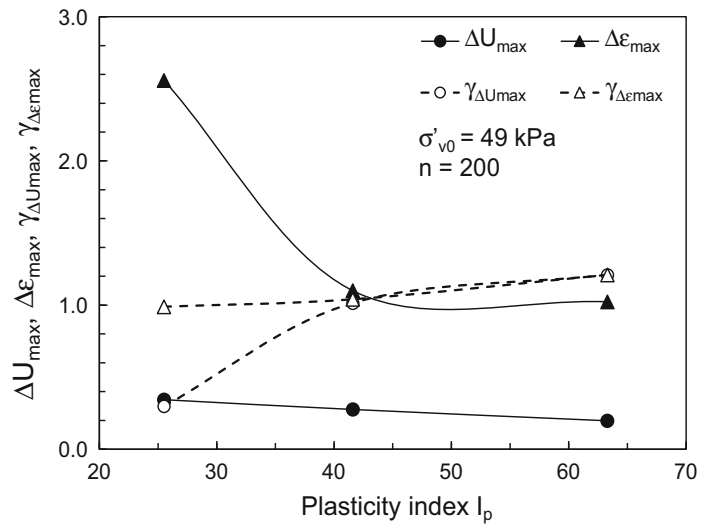

$\gamma_{\Delta U \max }$ and the difference remains for a wide range of $n$ (Matsuda et al. 2013a), meanwhile in Fig. 10, $\gamma_{\Delta U \max }$ equals to $\gamma_{\Delta \varepsilon \max }$ for the case of Tokyo bay clay and Kitakyushu clay.

\section{Development of a pore water pressure model for uni-directional and multi-directional cyclic shears on clays with different Atterberg's limits}

\subsection{Equation showing the pore water pressure accumulation}

Ohara et al. (1984), Ohara and Matsuda (1988), Matsuda (1997) and Matsuda and Nagira (2000) proposed and developed an equation based on the results for Kaolinite clay with low plasticity, which shows the relations between $U_{d y n} / \sigma_{v 0}^{\prime}$ and $n$ as follows:

$$
\frac{U_{d y n}}{\sigma_{v 0}^{\prime}}=\frac{n}{\alpha+\beta n}
$$

where $\alpha$ and $\beta$ are the experimental parameters and related to the shear strain amplitude $\gamma$ as follows:

$$
\begin{gathered}
\alpha=A(\gamma)^{m} \\
\beta=\frac{\gamma}{B+C \gamma}
\end{gathered}
$$

The experimental constants $A, B, C$ and $m$ in Eqs. (6) and (7) can be determined by applying the curve-fitting method on the results of uni-directional and multi-directional cyclic simple shear tests.

\subsection{Estimation of cyclic shear-induced pore water pressure on clays with different Atterberg's limits}

By using Eq. (5), the cyclic shear-induced pore water pressure was estimated for clays with a wide range of Atterberg's limits. In Fig. 11, observed results of the relationships between $U_{d y n} / \sigma_{v 0}^{\prime}$ and $n$ are shown by symbols and the calculated ones by using Eq. (5) are plotted 
(a)

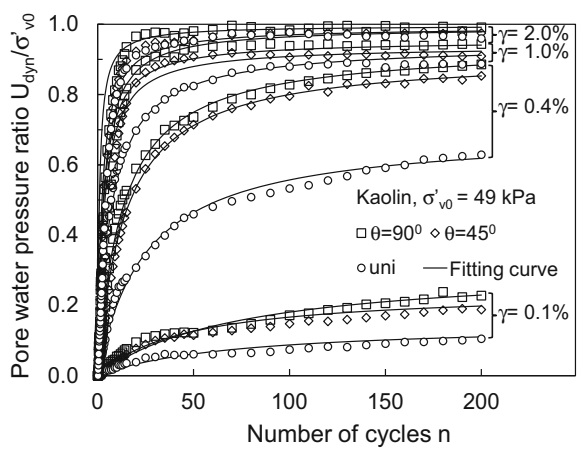

(c) (b)

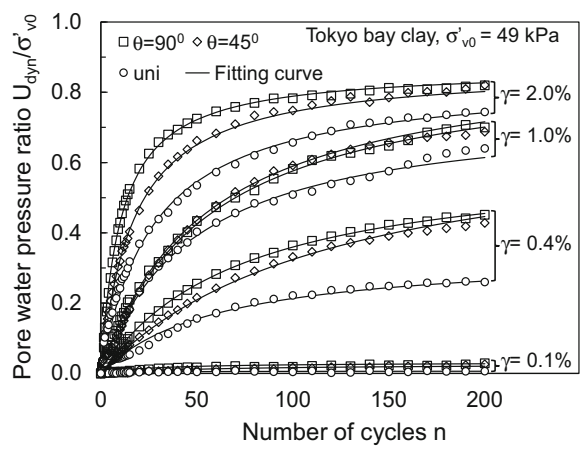

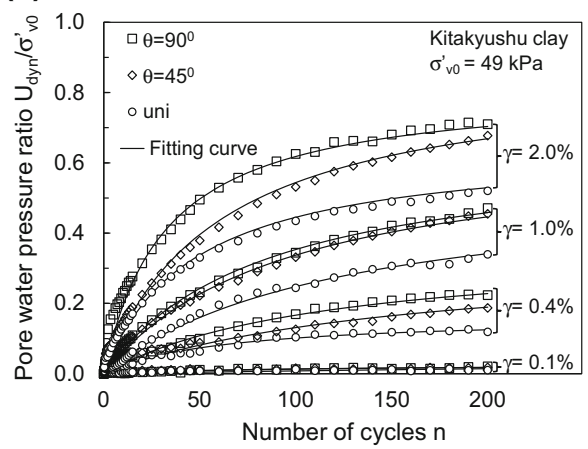

Fig. 11 Relations between $U_{d y n} / \sigma_{v 0}^{\prime}$ and $n$ for a Kaolin, b Tokyo bay clay and $\mathbf{c}$ Kitakyushu clay subjected to uni-directional and multi-directional cyclic shears

(a)

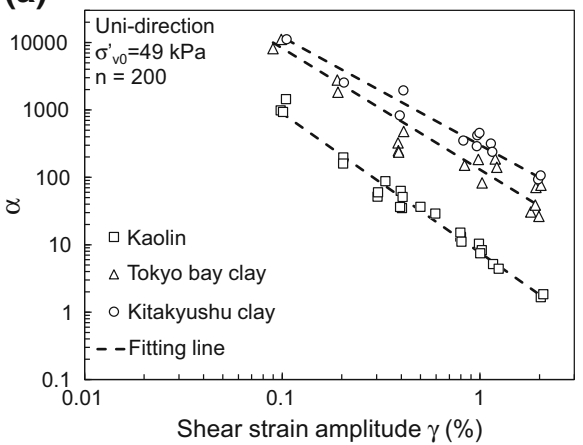

(b)

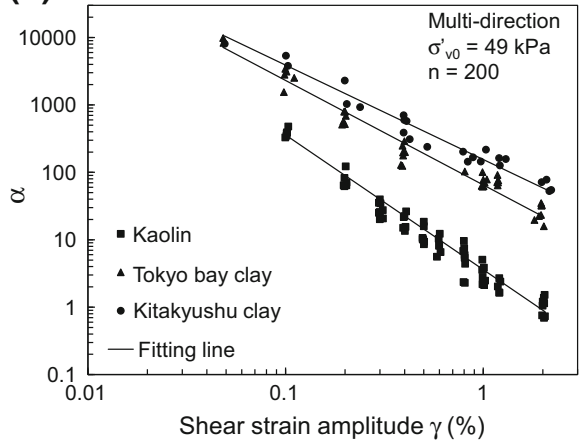

Fig. 12 Relations between $\alpha$ and $\gamma$ for clays subjected to $\mathbf{a}$ uni-directional and $\mathbf{b}$ multi-directional cyclic shears

by solid curves for Kaolin, Tokyo bay clay and Kitakyushu clay. Reasonable results are obtained in Fig. 11 (for $\gamma=0.1,0.4,1.0$ and 2.0\%). So, it is possible to find the relations of the experimental parameters $\alpha$ and $\gamma / \beta$ versus $\gamma$ in Eqs. (6) and (7), as shown by plots in Figs. 12 and 13 in which dashed and solid lines are the fitted lines for uni-directional and 
(a)

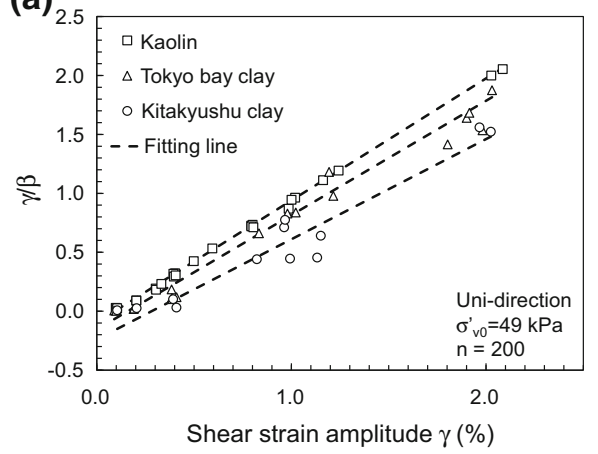

(b)

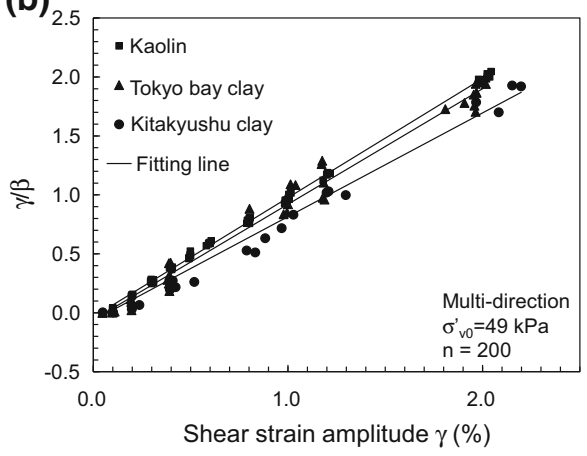

Fig. 13 Relations between $\gamma / \beta$ and $\gamma$ for clays subjected to a uni-directional and $\mathbf{b}$ multi-directional cyclic shears

Table 3 Experimental constants $A, B, C$ and $m$

\begin{tabular}{llrlll}
\hline Cyclic shear direction & Soil & \multicolumn{1}{l}{$A$} & \multicolumn{1}{l}{$B$} & \multicolumn{1}{l}{ C } & \multicolumn{1}{l}{. } \\
\hline Uni-direction & Kaolin & 7.0 & -0.0800 & 1.030 & -2.50 \\
& Tokyo bay clay & 130.0 & -0.1553 & 0.970 & -1.80 \\
& Kitakyushu clay & 300.0 & -0.2400 & 0.850 & -1.60 \\
Multi-direction & Kaolin & 3.9 & -0.0500 & 1.018 & -2.20 \\
& Tokyo bay clay & 65.0 & -0.0600 & 0.980 & -1.55 \\
& Kitakyushu clay & 155.0 & -0.0650 & 0.880 & -1.40 \\
\hline
\end{tabular}

multi-directional cyclic shear results, respectively. Then, the experimental constants $A, B$, $C$ and $m$ are summarized in Table 3 .

Figure 14 shows the results calculated by Eq. (5), in which solid lines are for the multidirectional cyclic shear and dashed lines are for the uni-directional one, respectively. The calculated results agree well with the observed ones and therefore the applicability of the above development on Eq. (5) is confirmed.

\subsection{Development of a model for cyclic shear-induced pore water pressure concerning the effect of Atterberg's limits}

In order to develop a new method to estimate the earthquake-induced pore water pressure more easily, based on the reasonable agreements between observed results and estimated ones as shown in Fig. 14, the experimental constants $A, B, C$ and $m$ in Table 3 are plotted against the plasticity index $I_{p}$ in Fig. 15, in which fitting lines follow the equations as shown in Table 4. Although number of plots is still limited, the plasticity index is possible to be incorporated into Eq. (5) and the pore water pressure accumulated in clays, at least for the range of $I_{p}$ from 25.5 to 63.8, can be estimated for both cases of uni-directional and multi-directional cyclic shears. Relationships between $U_{d y n} / \sigma_{v 0}^{\prime}$ and $\gamma$ are replotted in Fig. 16a for Kaolin, Tokyo bay clay and Kitakyushu clay. Symbols in this figure show the observed results and solid and dashed lines correspond to the estimated ones by using the 
Fig. 14 Relations between $U_{d y n} /$ $\sigma_{v 0}^{\prime}$ and $\gamma$ for clays with different Atterberg's limits subjected to uni-directional and multidirectional cyclic shears

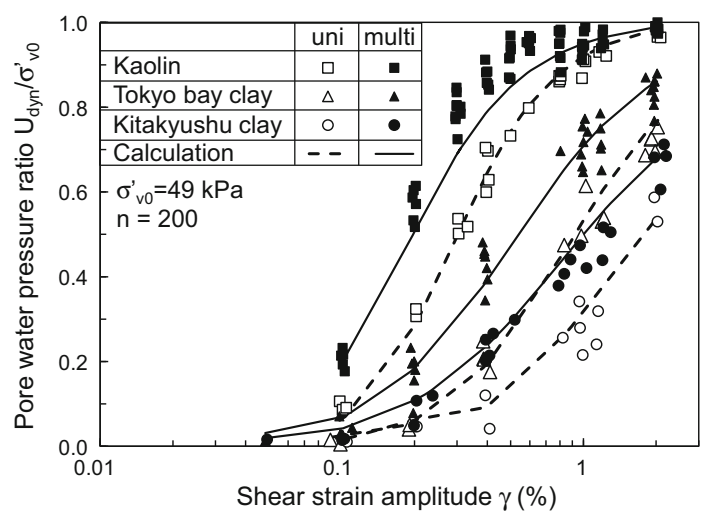

(a)

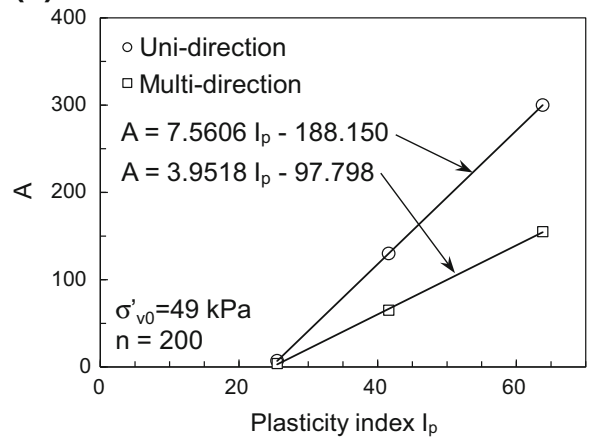

(c)

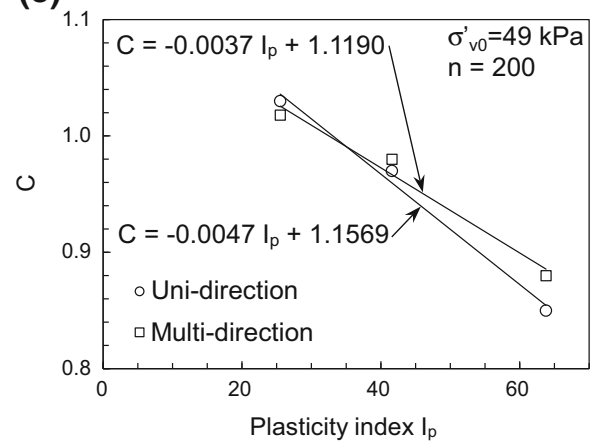

(b)

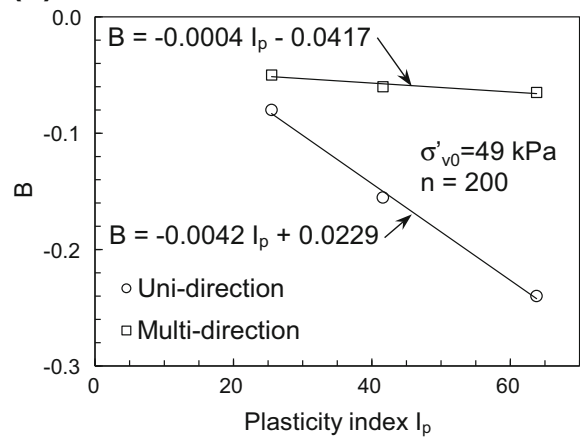

(d)

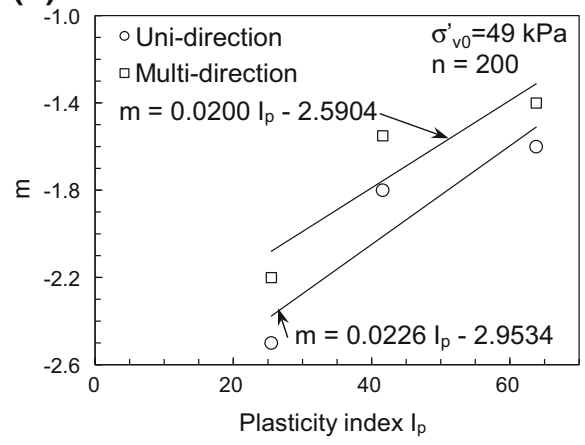

Fig. 15 Changes of a $A, \mathbf{b} B, \mathbf{c} C$ and $\mathbf{d} m$ with $I_{p}$

relations in Table 4. Further comparisons between the observed and estimated results are also shown in Fig. 16b. The accuracy of the calculation can be confirmed based on the reasonable agreements in Fig. 16 and therefore, the applicability of Eq. (5) to estimate the pore water pressure accumulation is confirmed for uni-directional and multi-directional cyclic shears on soft clays with a wide range of Atterberg's limits. 
Table 4 Experimental constants $A, B, C$ and $m$ in relation to $I_{p}$

\begin{tabular}{lll}
\hline Experimental constant & Uni-direction & Multi-direction \\
\hline$A$ & $A=7.5606 I_{p}-188.150$ & $A=3.9518 I_{p}-97.798$ \\
$B$ & $B=-0.0042 I_{p}+0.0229$ & $B=-0.0004 I_{p}-0.0417$ \\
$C$ & $C=-0.0047 I_{p}+1.1569$ & $C=-0.0037 I_{p}+1.1190$ \\
$m$ & $m=0.0226 I_{p}-2.9534$ & $m=0.0200 I_{p}-2.5904$ \\
\hline
\end{tabular}

(a)

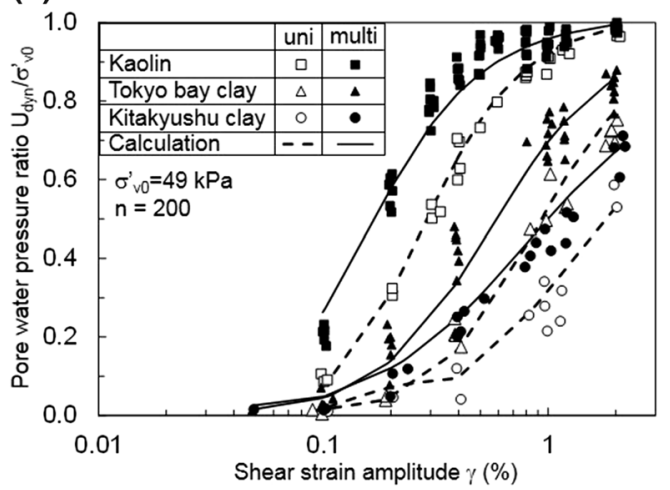

(b)

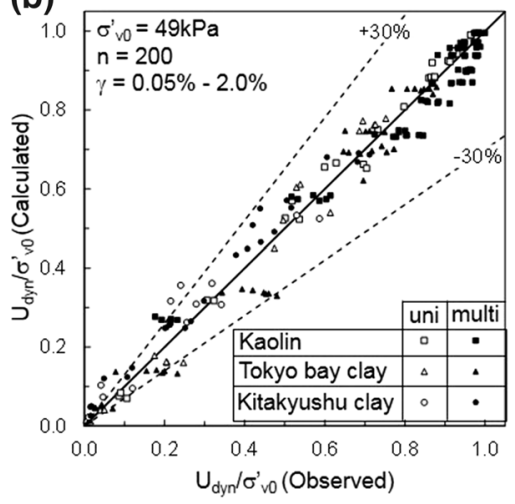

Fig. 16 Comparisons between observed and calculated results for the relations of $U_{d y n} / \sigma_{v 0}^{\prime}$ versus $\gamma$ on clays with a wide range of Atterberg's limits subjected to undrained uni-directional and multi-directional cyclic shears

\section{Prediction of post-earthquake settlement of clay layers}

\subsection{Equation for estimating the cyclic shear-induced settlement of clay}

When soft clay layers are subjected to strong cyclic shears by an earthquake, the cyclic shear-induced pore water pressure is accumulated inside the layers and due to its dissipation, the settlement occurs. The estimation method for the cyclic shear-induced settlement of clay layers has been widely developed (Ohara and Matsuda 1988; Matsuda 1997; Matsuda and Nagira 2000; Matsuda et al. 2013a, b; Yasuhara and Andersen 1991; Yasuhara et al. 1992, 2001; Yasuhara 1995; Hyodo et al. 1992), in which Ohara and Matsuda (1988) derived Eq. (8) where the settlement in strain $\left(\varepsilon_{V}, \%\right)$ induced by the undrained uni-directional cyclic shear is a function of the so-called "cyclic recompression index, $C_{d y n}$ " and "stress reduction ratio, $S R R$ ".

$$
\varepsilon_{v}=\frac{\Delta h}{h_{0}}=\frac{\Delta e}{1+e_{0}}=\frac{C_{d y n}}{1+e_{0}} \log \left(\frac{1}{1-\frac{U_{d y n}}{\sigma_{v 0}^{\prime}}}\right)=\frac{C_{d y n}}{1+e_{0}} \log S R R
$$

where $\Delta h$ is the settlement, $h_{0}$ is the initial height of the specimen, $\Delta e$ is the change of void ratio, $e_{0}$ is the initial void ratio and $S R R$ is defined by $1 /\left(1-U_{d y n} / \sigma_{v 0}^{\prime}\right)$. 


\subsection{Change of void ratio induced by cyclic shears}

The changes of void ratio $(\Delta e)$ on Kaolin, Tokyo bay clay and Kitakyushu clay after undrained uni-directional and multi-directional cyclic shears are shown against $S R R$ in Fig. 17 for a wide range of $\gamma$. In this figure, symbols show observed results, and solid and dashed lines correspond to the calculated ones by using Eq. (8) in which SRR was determined by using Eq. (5). Although the observed results of Kaolin show some scattering, the calculated lines are on the observed plots for all cases.

It has been reported that, in the case of the uni-directional cyclic shear, there is a linear relationships between $\Delta e$ and the logarithm of $S R R$ irrespective of number of strain cycles and shear strain amplitude (Ohara and Matsuda 1988). In Fig. 17, for three kinds of clays with different plasticity indices, different values of cyclic recompression index were obtained for uni-directional cyclic shear $\left(C_{d y n U}\right)$ and multi-directional one $\left(C_{d y n M}\right)$ and so the relations are affected by the direction of cyclic shear strain. The obtained values of $C_{d y n U}$ and $C_{d y n M}$ are summarized in Table 5 indicating their increasing tendency with the plasticity index and when comparing with the compression index $C_{c}, C_{d y n U}=0.180 C_{c}-$ $0.233 C_{c}$ and $C_{d y n M}=0.198 C_{c}-0.250 C_{c}$ are obtained. These relations are very close to those as $C_{d y n}=0.225 C_{c}$ which has been proposed by using cyclic direct-simple shear tests on normally consolidated Drammen clay (Yasuhara and Andersen 1991; Yasuhara et al. 2001).

In addition, by using a series of undrained uni-directional and multi-directional cyclic shear tests on Kaolinite clay, Matsuda et al. (2013a) showed that the change of the void ratio in the recompression stage is independent of shear strain amplitude but being affected by the cyclic shear direction. Consequently, authors have confirmed the existence of the difference between $C_{d y n M}$ and $C_{d y n U}$ for a wide range of shear strain amplitude $(\gamma=0.05-3.0 \%)$ and number of cycles $(n=10-200)$. Furthermore, by performing the consolidation test after undrained uni-directional cyclic simple shear on normally consolidated Kaolin and natural clay, Ohara and Matsuda (1988) and Yasuhara and Andersen (1991) indicated that the recompression curve in the $e-\log P$ relations does not approach the virgin compression curve even when the recompression stress reaches considerably larger than the pre-consolidation one and this phenomenon remains over a long period. Therefore, although the differences between $C_{d y n M}$ and $C_{d y n U}$ in Fig. 17 and Table 5 are relatively small and there is a tendency

Fig. 17 Relations between $\Delta e$ and $S R R$ of clays subjected to undrained uni-directional and multi-directional cyclic shears

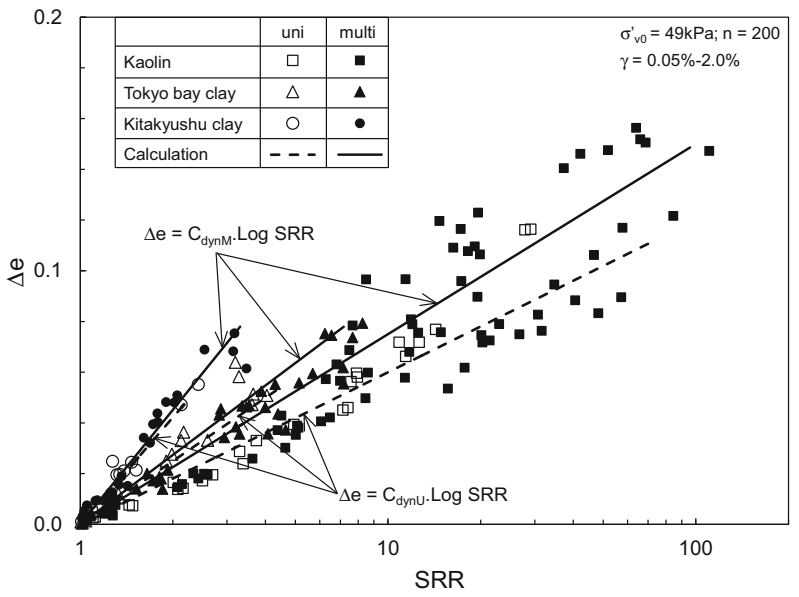


Table 5 Cyclic recompression index of clays subjected to uni-directional and multi-directional cyclic shears

\begin{tabular}{llll}
\hline Cyclic recompression index & Kaolin & Tokyo bay clay & Kitakyushu clay \\
\hline Uni-direction, $C_{d y n U}$ & 0.060 & 0.083 & 0.140 \\
Multi-direction, $C_{d y n M}$ & 0.075 & 0.091 & 0.150 \\
\hline
\end{tabular}

of decreasing with $I_{p}$, these differences should be taken into account when estimating the post-cyclic settlement and the effect of the multi-directional cyclic shear on the recompression characteristics of clay should be further recognized.

\subsection{Estimation of post-cyclic settlement concerning the effect of Atterberg's limits}

To clarify the effects of Atterberg's limits on the cyclic recompression index, relationships between $C_{d y n U}$ and $C_{d y n M}$ and the plasticity index are shown in Fig. 18.

Relationships between $\varepsilon_{v}$ and $\gamma$ are shown in Fig. 19a for clays subjected to undrained uni-directional and multi-directional cyclic shears. Symbols in this figure show observed results, and solid and dashed lines correspond to the predicted ones by using Eq. (8) where $C_{d y n U}$ and $C_{d y n M}$ were calculated by using the relations in Table 6. To confirm the applicability of Eq. (8) more in detail, relationships between the observed results and calculated ones are shown in Fig. 19b. Reasonable agreements are seen for the whole range of $\gamma$, and therefore, the developed method is valid for estimating the post-cyclic settlement of clays with a wide range of plasticity indices.

\subsection{Prediction of earthquake-induced pore water pressure and post- earthquake settlement of a clay layer concerning the effect of cyclic shear direction and its irregularity}

Several series of multi-directional cyclic shear tests were carried out on Kaolin by using the irregular strain-time histories of Hyogo-ken Nanbu earthquake 1995. The orbit of these irregular strain-time histories has been shown in Fig. 1b. To clarify the effect of cyclic shear strain direction on the earthquake-induced pore water pressure accumulation and the settlement of clayey soil, cyclic shear tests were performed under the undrained condition and followed by the drainage, in which the maximum shear strain amplitudes in NS and

Fig. 18 Changes of $C_{d y n U}$ and $C_{d y n M}$ with $I_{p}$

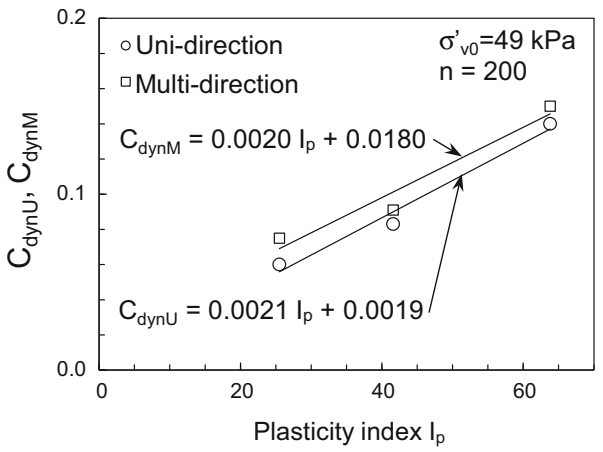


(a)

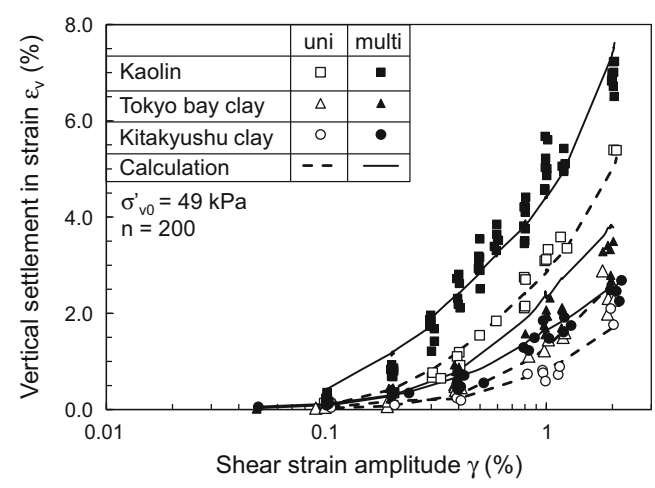

(b)

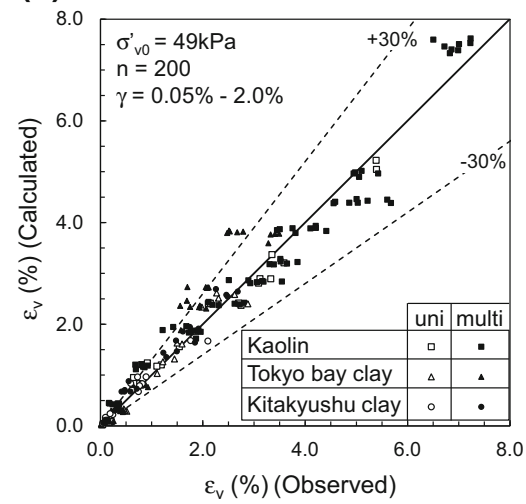

Fig. 19 Comparisons between observed and calculated results for the relations of $\varepsilon_{v}$ versus $\gamma$ on clays with a wide range of Atterberg's limits subjected to undrained uni-directional and multi-directional cyclic shears

Table $6 C_{d y n U}$ and $C_{d y n M}$ in relation to $I_{p}$

\begin{tabular}{ll}
\hline Cyclic shear direction & Relation \\
\hline Uni-direction & $C_{d y n U}=0.0021 I_{p}+0.0019$ \\
Multi-direction & $C_{d y n M}=0.0020 I_{p}+0.0180$ \\
\hline
\end{tabular}

$E W$ directions were changed, covering from lower to higher levels based on the original ones. The method of irregular multi-directional cyclic shear tests has been shown more in detail by Matsuda et al. (2013b). The changes of pore water pressure during undrained cyclic shear and the vertical settlement after cyclic shear are shown in Fig. 20a, b for respective maximum shear strain amplitude $\left(\gamma_{\max }\right)$. Because the maximum shear strain amplitude in NS direction is larger than those in $E W$ direction, i.e. $\gamma_{\max N S}>\gamma_{\max E W}$ and so $\gamma_{\operatorname{maxNS}}$ is referred as the maximum shear strain amplitude of the earthquake, i.e. $\gamma_{\max }=\gamma_{\operatorname{maxNS}}$ (Matsuda et al. 2013b). In Fig. 20, the observed results of $\gamma_{\max }=0.38 \%$ was newly added to the previous ones $\left(\gamma_{\max }=0.57,1.15\right.$ and $\left.2.30 \%\right)$ and it is evident that the

(a)

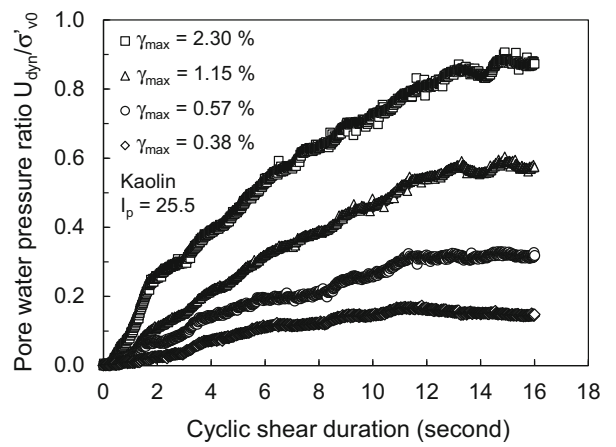

(b)

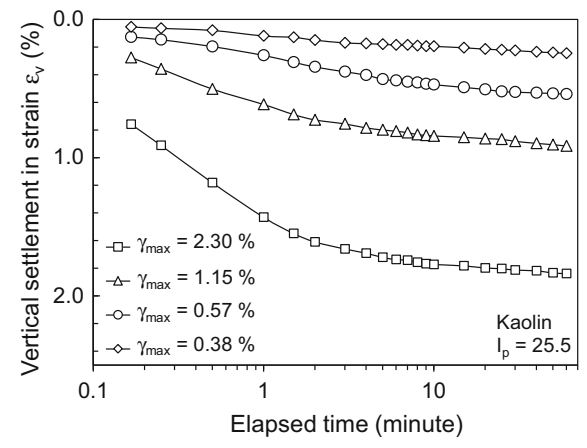

Fig. 20 a Pore water pressure accumulation and b post-cyclic settlement of Kaolin under irregular multidirectional cyclic shear at various maximum shear strain amplitudes 
pore water pressures accumulate during the earthquake continuously and that the larger the maximum shear strain amplitude, the higher the earthquake-induced pore water pressure accumulation and settlement.

In order to show an example of practical applicability of the methods, the developed model for multi-directional cyclic shear-induced pore water pressure and the settlement was applied to the irregular multi-directional cyclic shear test results mentioned above and the calculated results were compared with the observed ones. The first step of the method is to determine the equivalent effective number of cycles $\left(N_{c y}\right)$ and the equivalent uniform shear strain amplitude $\left(\gamma_{d y n}\right)$ of the irregular shear strain-time histories for its transformation into the equivalent uniform ones. The equivalent number of cycles should be calculated directly from the acceleration records by using the peak-counting definitions (Malhotra 2002; Hancock and Bommer 2005), meanwhile the equivalent uniform shear strain amplitude has been confirmed as a function of the maximum shear strain amplitude, such as $\gamma_{d y n}=0.65 \gamma_{\max }$ (Seed et al. 1975; Annaki and Lee 1977) or $\gamma_{d y n}=F\left(\gamma_{\max }\right)^{G}$ where $F$ and $G$ are the experimental parameters (Matsuda and Hoshiyama 1992). The transformation procedure by using these methods has been developed and applied to Hyogo-ken Nanbu earthquake 1995 by Matsuda et al. (2013b) and the obtained results of $N_{c y}$ and $\gamma_{d y n}$ are shown in Table 7 for various maximum shear strain amplitudes.

The changes of pore water pressure ratio $\left(U_{d y n} / \sigma_{v 0}^{\prime}\right)$ with $N_{c y}$ during undrained cyclic shear are shown in Fig. 21a and the accumulation of $U_{d y n} / \sigma_{v 0}^{\prime}$ after cyclic shear (at $N_{c y}=8.9$ ) are plotted against $\gamma_{d y n}$ in Fig. $21 \mathrm{~b}$ for Kaolin subjected to irregular multidirectional cyclic shear with various levels of $\gamma_{\max }$. Symbols in these figures correspond to observed results, and dashed and solid lines are the calculated ones by using Eqs. (5)-(7) in which $n$ and $\gamma$ were replaced by $N_{c y}$ and $\gamma_{d y n}$, respectively, and the experimental constant $A$, $B, C, m$ were determined by using relations in Table 4 for the case of multi-direction. In Fig. 21a, when comparing the observed and calculated results for the changes of $U_{d y n} / \sigma_{v 0}^{\prime}$ during earthquakes, some differences are seen. On the other hand, reasonable agreements are seen in Fig. 21b and therefore the validity of the developed model for estimating the earthquake-induced pore water pressure accumulation is confirmed for a wide range of $\gamma_{\text {max }}$. In addition to the accumulation component of $U_{d y n} / \sigma_{v 0}^{\prime}$ which is focused in the current developed model, the changes of $U_{d y n} / \sigma_{v 0}^{\prime}$ during undrained cyclic shear is also affected by the so-called ruffling component (Matsuda et al. 2013b) and this is considered to be one of reasons for the differences between the estimated and observed results in Fig. 21a.

After finishing the undrained irregular multi-directional cyclic shear, the drainage was allowed to simulate the pore water pressure dissipation after earthquakes and at the same time, the settlement of soil specimen was measured. In Fig. 22a, b, the change of void ratio $(\Delta e)$ and the post-earthquake settlement $\left(\varepsilon_{v}, \%\right)$ are plotted against $S R R$ and $\gamma_{d y n}$. The

Table 7 Equivalent number of cycles and shear strain amplitude (Matsuda et al. 2013b)

\begin{tabular}{llll}
\hline $\begin{array}{l}\text { Maximum shear strain } \\
\text { amplitude, } \gamma_{\max }(\%)\end{array}$ & $\begin{array}{l}\text { Equivalent number } \\
\text { of cycles, } N_{c y}\end{array}$ & \multicolumn{2}{l}{ Equivalent shear strain amplitude, $\gamma_{\text {dyn }}(\%)$} \\
\cline { 2 - 3 } & 8.9 & $\gamma_{\text {dyn }}=0.65 \gamma_{\max }$ & $\gamma_{\text {dyn }}=F\left(\gamma_{\max }\right)^{G}$ \\
\hline $0.38^{\mathrm{a}}$ & & 0.25 & 0.25 \\
0.57 & 0.37 & 0.35 \\
1.15 & 0.75 & 0.61 \\
2.30 & 1.50 & 1.05 \\
\hline
\end{tabular}

a Observed data of $\gamma_{\max }=0.38 \%$ was added to the previous data on the same Kaolin 
(a)

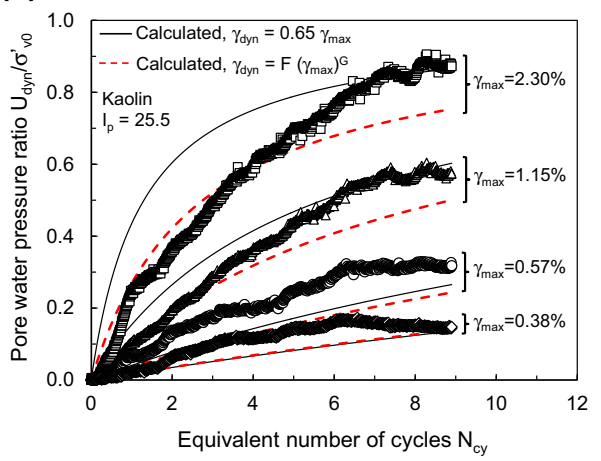

(b)

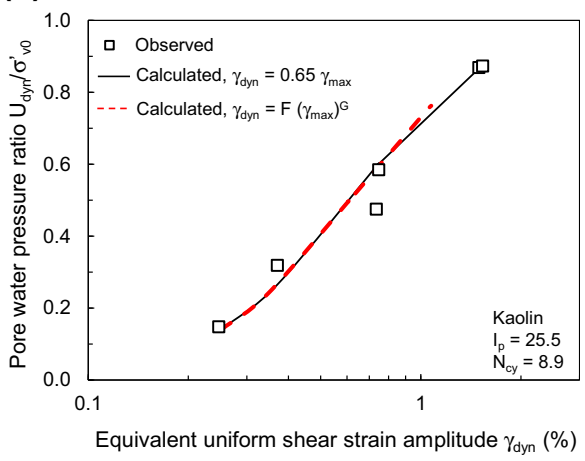

Fig. 21 Relations of $U_{d y n} / \sigma_{v 0}^{\prime}$ versus $\mathbf{a} N_{c y}$ and $\mathbf{b} \gamma_{d y n}$ for Kaolin subjected to irregular multi-directional cyclic shear at various levels of $\gamma_{\max }$

(a)

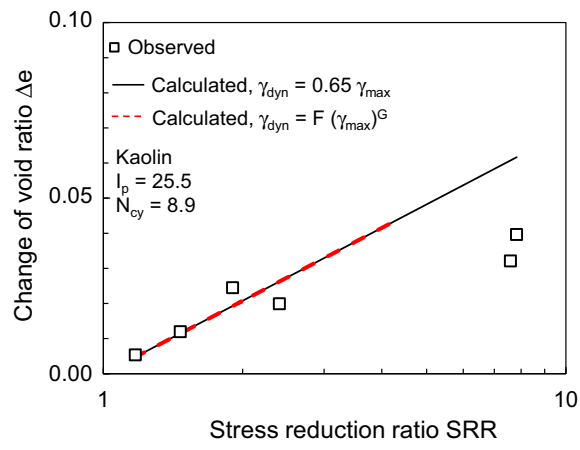

(b)

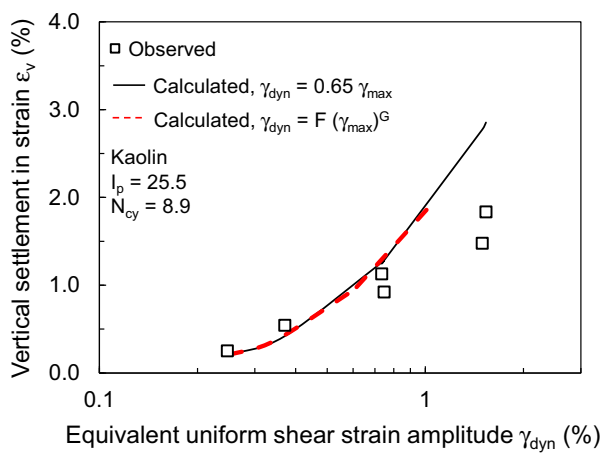

Fig. 22 Relations of $\mathbf{a} \Delta e$ versus $S R R$ and $\mathbf{b} \varepsilon_{v}$ versus $\gamma_{d y n}$ for Kaolin subjected to irregular multi-directional cyclic shear at various levels of $\gamma_{\max }$

calculated results shown by dashed and solid lines were obtained by using $\gamma_{d y n}=0.65 \gamma_{\max }$ and $\gamma_{d y n}=F\left(\gamma_{\max }\right)^{G}$, respectively. The calculated results agree reasonably with the observed ones and therefore, the validity of the developed model for predicting postearthquake settlement can be confirmed.

\section{Conclusions}

Saturated clay specimens with different Atterberg's limits were prepared for uni-directional and multi-directional cyclic shear tests under undrained conditions, and the effects of Atterberg's limits on the pore water pressure accumulation and the recompression were evaluated. Then a model for the pore water pressure accumulation and the post-earthquake settlement under multi-directional cyclic shears was developed. The main conclusions are as follows:

The pore water pressure accumulation and the post-cyclic settlement induced by multidirectional cyclic shear increase considerably to a higher level compared with those 
induced by the uni-directional ones and therefore, the effects of cyclic shear direction on the cyclic shear-induced pore water pressure and settlement are confirmed for clays with a wide range of Atterberg's limits. This behavior is different from those of saturated sands, in which the effect of cyclic shear direction is negligible when $\gamma \geq 0.3 \%$.

For the pore water pressure ratio and the settlement in strain between multi-directional and uni-directional cyclic shears, by using its ratio and the differences the effects of cyclic shear direction on such properties were clarified in relation to the shear strain amplitude and the plasticity index.

When the plasticity index of clay increases, the pore water pressure accumulation and the post-cyclic settlement decrease. This effect of the plasticity index correlates well with experimental constants, and a model for cyclic shear-induced pore water pressure and settlement was developed for clays with a wide range of Atterberg's limits.

The practical applicability of the developed model was confirmed by applying the earthquake-induced irregular multi-directional cyclic shear strains.

Acknowledgements A part of this study is funded by Vietnam National Foundation for Science and Technology Development (NAFOSTED) under Grant Number 105.99-2014.04 and the experimental works were also supported by the students who graduated Yamaguchi University. The authors would like to express their gratitude to them.

Open Access This article is distributed under the terms of the Creative Commons Attribution 4.0 International License (http://creativecommons.org/licenses/by/4.0/), which permits unrestricted use, distribution, and reproduction in any medium, provided you give appropriate credit to the original author(s) and the source, provide a link to the Creative Commons license, and indicate if changes were made.

\section{References}

Annaki M, Lee KL (1977) Equivalent uniform cycle concept for soil dynamics. J Geotech Eng Div ASCE 103(GT6):549-564

Ansal A, Iyisan R, Yildirim H (2001) The cyclic behavior of soils and effects of geotechnical factors in microzonation. Soil Dyn Earthq Eng 21(5):445-452

DeGroot DJ, Ladd CC, Germaine JT (1996) Undrained multidirectional direct simple shear behavior of cohesive soil. J Geotech Eng ASCE 122(2):91-98

Hancock J, Bommer J (2005) The effective number of cycles of earthquake ground motion. Earthq Eng Struct Dyn 34:637-664

Hyde AFL, Yasuhara K, Hirao K (1993) Stability criteria for marine clay under one-way cyclic loading. J Geotech Eng ASCE 119(11):1771-1789

Hyodo M, Yasuhara K, Hirao K (1992) Prediction of clay behavior in undrained and partially drained cyclic triaxial tests. Soils Found 32(4):117-127

Hyodo M, Yamamoto Y, Sugiyama M (1994) Undrained cyclic shear behaviour of normally consolidated clay subjected to initial static shear stress. Soils Found 34(4):1-11

Hyodo M, Hyde AFL, Yamamoto Y, Fujii T (1999) Cyclic shear strength of undisturbed and remoulded marine clays. Soils Found 39(2):45-58

Ishihara K, Yamazaki F (1980) Cyclic simple shear tests on saturated sand in multi-directional loading. Soils Found 20(1):45-59

Ishihara K, Yoshimine M (1992) Evaluation of settlements in sand deposits following liquefaction during earthquakes. Soils Found 32(1):173-188

Japan Road Association (2002) Specifications for highway bridges, part 5: Seismic design

Konagai K, Kiyota T, Suyama S, Asakura T, Shibuya K, Eto C (2013) Maps of soil subsidence for Tokyo bay shore areas liquefied in the March 11th, 2011 off the Pacific Coast of Tohoku Earthquake. Soil Dyn Earthq Eng 53:240-253

Malhotra PK (2002) Cyclic-demand spectrum. Earthq Eng Struct Dyn 31:1441-1457

Matasovic N, Vucetic M (1992) A pore pressure model for cyclic straining of clay. Soils Found 32(3):156-173 
Matasovic N, Vucetic M (1995) Generalized cyclic degradation pore pressure generation model for clays. J Geotech Eng ASCE 121(1):33-42

Matsuda H (1997) Estimation of post-earthquake settlement-time relations of clay layers. J JSCE Div C 568(III-39):41-48 (in Japanese)

Matsuda H, Hoshiyama E (1992) Uniform strain series equivalent to seismic strain. In: Proceedings of 10th world conference on earthquake engineering, Rotterdam, pp 1329-1334

Matsuda H, Nagira H (2000) Decrease in effective stress and reconsolidation of saturated clay induced by cyclic shear. J JSCE Div C 659(III-52):63-75 (in Japanese)

Matsuda H, Ohara S (1989) Threshold strain of clay for pore pressure buildup. In: Proceedings of 12th world conference on soil mechanics and foundation engineering, Rio De Janeiro, pp 127-130

Matsuda H, Shinozaki H, Okada N, Takamiya K, Shinyama K (2004) Effects of multi-directional cyclic shear on the post-earthquake settlement of ground. In: Proceedings of 13th world conference on earthquake engineering, Vancouver, paper no 2890

Matsuda H, Andre PH, Ishikura R, Kawahara S (2011) Effective stress change and post-earthquake settlement properties of granular materials subjected to multi-directional cyclic simple shear. Soils Found 51(5):873-884

Matsuda H, Nhan TT, Ishikura R, Inazawa T (2012) New criterion for the liquefaction resistance under strain-controlled multi-directional cyclic shear. In: Proceedings of 15th world conference on earthquake engineering, Lisboa, paper no 4149

Matsuda H, Nhan TT, Ishikura R (2013a) Excess pore water pressure accumulation and recompression of saturated soft clay subjected to uni-directional and multi-directional cyclic simple shears. J Earthq Tsunami 7(4):1-22

Matsuda H, Nhan TT, Ishikura R (2013b) Prediction of excess pore water pressure and post-cyclic settlement on soft clay induced by uni-directional and multi-directional cyclic shears as a function of strain path parameters. Soil Dyn Earthq Eng 49:75-88

Matsui T, Bahr MA, Abe N (1992) Estimation of shear characteristics degradation and stress-strain relationship of saturated clays after cyclic loading. Soils Found 32(1):161-172

Nhan TT, Matsuda H, Hara H, Sato H (2015) Normalized pore water pressure ratio and post-cyclic settlement of saturated clay subjected to undrained uni-directional and multi-directional cyclic shears. In: 10th asian regional conference of IAEG, Kyoto, Paper no 1081418

Ohara S, Matsuda H (1988) Study on the settlement of saturated clay layer induced by cyclic shear. Soils Found 28(3):103-113

Ohara S, Matsuda H, Kondo Y (1984) Cyclic simple shear tests on saturated clay with drainage. J JSCE Div C 352(III-2):149-158 (in Japanese)

Pyke R, Seed HB, Chan CK (1975) Settlement of sands under multidirectional shaking. J Geotech Eng ASCE 101(GT4):379-398

Sangrey DA, Henkel DJ, Esrig MI (1969) The effective stress response of a saturated clay soil to repeated loading. Can Geotech J 6(3):241-252

Seed HB, Idriss IM, Makdisi F, Banerjee J (1975) Representation of irregular stress time histories by equivalent uniform stress series in liquefaction analysis. Earthquake engineering research center report EERC 75-29, University of California, Berkeley

Talaganov KV (1996) Stress-strain transformations and liquefaction of sands. Soil Dyn Earthq Eng 15(7):411-418

Talesnick M, Frydman S (1992) Irrecoverable and overall strains in cyclic shear of soft clay. Soils Found 32(3):47-59

Tokimatsu K, Yoshimi Y (1982) Liquefaction of sand due to multi-directional cyclic shear. Soils Found 22(3):126-130

Vucetic MA, Dobry R (1991) Effect of soil plasticity on cyclic response. J Geotech Eng ASCE 117(1):89-107

Yasuhara K (1995) Consolidation and settlement under cyclic loading. In: Proceedings of international symposium on compression and consolidation of clayey soils, Hiroshima, pp 979-1001

Yasuhara K, Andersen KH (1991) Recompression of normally consolidated clay after cyclic loading. Soils Found 31(1):83-94

Yasuhara K, Yamanouchi T, Hirao K (1982) Cyclic strength and deformation of normally consolidated clay. Soils Found 22(3):77-91

Yasuhara K, Hirao K, Hyde AFL (1992) Effects of cyclic loading on undrained strength and compressibility of clay. Soils Found 32(1):100-116

Yasuhara K, Murakami S, Toyota N, Hyde AFL (2001) Settlements in fine-grained soils under cyclic loading. Soils Found 41(6):25-36 
Yildirim H, Ersan H (2007) Settlements under consecutive series of cyclic loading. Soil Dyn Earthq Eng 27:577-585

Yong RN, Japp RD (1969) Stress-strain behavior of clays in dynamic compression. Vibration effects of earthquake of soils and foundation. ASTM STP 450:233-262 